\title{
FENTANYL-OXYGEN ANAESTHESIA FOR CORONARY ARTERY SURGERY: CARDIOVASCULAR AND ANTIDIURETIC HORMONE RESPONSES
}

\author{
Theodore H. Stanley, Daniel M. Philbin, and Cecil H. Cocgins
}

HJGH DOSES OF FENTANYL $\left(50-100 \mu \mathrm{g} \cdot \mathrm{kg}^{-1}\right)$ pluS oxygen have recently been described as an attractive anaesthetic technique in patients with mitral valvular disease undergoing mitral valve replacement operations.' Fentanyl-oxygen anaesthesia is also being used in patients for coronary artery bypass operations. The cardiovascular and hormonal effects of fentanyl as a "complete" anaesthetic have not been carefully studied during anaesthesia and coronary artery operation. In this study we measured the cardiovascular and anti-diuretic hormone responses to anaesthetic doses of fentanyl and oxygen before and during operation in 14 patients undergoing coronary artery revascularization procedures.

\section{Methoos}

Fentanyl-oxygen is considered a standard anaesthetic technique at the University of Utah Medical Center; therefore, informed consent to perform the study was only required for drawing of blood samples. Informed written consent was obtained from each of the patients at the time of the pre-anaesthetic visit. Patients included in the study were ASA class III and scheduled to undergo elective coronary artery revascularization operations. The patients were unselected with respect to preoperative cardiovascular dynamics but all happened to have resting cardiac output greater than $4 \mathrm{l} / \mathrm{min}$. None had evidence

Theodore H. Stanley, M.D., Professor of Anesthesiology/Surgery, University of Utah College of Medicine.

Daniel M. Philbin, M.D., Assistant Professor of Anaesthesia, Massachusetts General Hospital and Harvard Medical School.

Cecil H. Coggins, M.D., Assistant Professor of Medicine, Massachusetts General Hospital and Harvard Medical School.

From the department of Anesthesiology, The University of Utah College of Medicine, Salt Lake City, Utah 84132 and the Departments of Anaesthesia and Medicine, The Massachusetts General Hospital and the Harvard Medical School, Boston, Massachusetts 02114 .

Canad. Anaesth. Soc. J., vol. 26, no. 3, May 1979 of significant hepatic, renal, pulmonary or central nervous system pathology.

All patients were premedicated with pentobaritone $(60-100 \mathrm{mg})$ and atropine $(0.3-0.5 \mathrm{mg})$ intramuscularly, 90 minutes before the scheduled operation. Prior to anaesthesia an intravenous line was established in an upper extremity, a central venous pressure catheter was placed percutaneously into the right atrium from the antecubital fossa or the neck and a radial or brachial artery catheter was inserted percutaneously and threaded 30 to $72 \mathrm{~cm}$ into the central aorta. The aortic pressure catheter was attached through an arterial pressure transducer to a central digital computer substation in the operating room. After appropriate dye dilution calibration as previously described, ${ }^{2}$ Warner's method of analyzing the central aortic pulse-pressure curve was used to determine cardiac output ( $Q T)$, heart rate (HR), stroke volume (SV), mean arterial blood pressure (BP), and peripheral arterial resistance (PVR) ${ }^{2}$

Following a 15-minute period of breathing pure oxygen a $10 \mathrm{ml}$ sample of venous blood was obtained for antidiuretic hormone (ADH) assay and SV, HR, Q $r, \overline{B P}$ and PVR were determined. Fentanyl was then administered intravenously, first at 50 to $100 \mu \mathrm{g} / \mathrm{min}$ for the first five minutes and then at $300 \mu \mathrm{g} / \mathrm{min}$, until the patients were unresponsive to verbal command and pinprick stimulation of the chest. Respiration was first assisted, and then controlled. Succinylcholine (1.5 $\mathrm{mg} \cdot \mathrm{kg}^{-1}$, intravenously) was then given, the trachea was intubated and respiration was controlled to maintain $\mathrm{Pa}_{\mathrm{CO}_{2}}$, between 3.99 and $4.66 \mathrm{kPa}$ ( 30 and 35 torr) as measured in aortic blood every 15-30 minutes. Additional fentanyl was administered at a rate of 150 to $200 \mu \mathrm{g} / \mathrm{min}$, until each patient had received $60 \mu \mathrm{g} \cdot \mathrm{kg}^{-1}$. Following this, the surgical procedure began. Additional blood samples were obtained for ADH assay and cardiovascular dynamics were recorded after each $10 \mu \mathrm{g} \cdot \mathrm{kg}^{-1}$ of fentanyl, before and two minutes after tracheal intubation, before and five minutes after initiation of operation and before and 15 and 60 minutes after beginning car168 
TABLE I

Cardiovascular and Antidiuretic Hormone Responses During Fentanyl-Oxygen Anaesthesia and Operation (MEAN + SD)

\begin{tabular}{|c|c|c|c|c|c|c|c|c|c|}
\hline & \multirow[b]{2}{*}{ Control } & \multicolumn{4}{|c|}{ Fentanyl $\mu \mathrm{g} \cdot \mathrm{kg}^{-1}$} & \multirow{2}{*}{$\begin{array}{l}\text { Surgical } \\
\text { stimulation }\end{array}$} & \multirow{2}{*}{$\begin{array}{l}\text { Before } \\
\text { bypass }\end{array}$} & \multirow{2}{*}{$\begin{array}{c}\text { Bypass } \\
15\end{array}$} & \multirow{2}{*}{$(\min )$} \\
\hline & & 20 & intubation & 40 & 60 & & & & \\
\hline $\begin{array}{l}\text { Heart rate } \\
\text { (beats/min) }\end{array}$ & $\begin{array}{l}68 \\
\pm 9\end{array}$ & $\begin{array}{l}59^{*} \\
\pm 6\end{array}$ & $\begin{array}{l}59^{*} \\
\pm 7\end{array}$ & $\begin{array}{l}60^{*} \\
\pm 7\end{array}$ & $\begin{array}{l}60^{*} \\
\pm 8\end{array}$ & $\begin{array}{l}58^{*} \\
\pm 7\end{array}$ & $\begin{array}{l}60^{*} \\
\pm 8\end{array}$ & - & - \\
\hline $\begin{array}{l}\text { Stroke volume } \\
\text { (mi) }\end{array}$ & $\begin{array}{l}66 \\
\pm 10\end{array}$ & $\begin{array}{l}72 \\
\pm 11\end{array}$ & $\begin{array}{l}71 \\
\pm 9\end{array}$ & $\begin{array}{l}72 \\
\pm 11\end{array}$ & $\begin{array}{l}70 \\
\pm 10\end{array}$ & $\begin{array}{l}71 \\
\pm 11\end{array}$ & $\begin{array}{l}70 \\
\pm 11\end{array}$ & - & - \\
\hline $\begin{array}{l}\text { Cardiac output } \\
\text { (1 min) }\end{array}$ & $\begin{array}{l}4.5 \\
\pm 0.4\end{array}$ & $\begin{array}{l}4.3 \\
\pm 0.5\end{array}$ & $\begin{array}{l}4.2 \\
\pm 0.6\end{array}$ & $\begin{array}{l}4.4 \\
\pm 0.6\end{array}$ & $\begin{array}{l}4.3 \\
\pm 0.5\end{array}$ & $\begin{array}{l}4.3 \\
\pm 0.6\end{array}$ & $\begin{array}{l}4.2 \\
\pm 0.5\end{array}$ & $\begin{array}{l}4.3 \\
\pm 0.7\end{array}$ & $\begin{array}{l}4.4 \\
\pm 0.7\end{array}$ \\
\hline $\begin{array}{l}\text { Mean blood pressure } \\
\text { (torr) }\end{array}$ & $\begin{array}{l}108 \\
\pm 10\end{array}$ & $\begin{array}{l}99^{*} \\
\pm 9\end{array}$ & $\begin{array}{r}98 * \\
\pm 9\end{array}$ & $\begin{array}{l}99 * \\
\pm 9\end{array}$ & $\begin{array}{l}98^{*} \\
\pm 9\end{array}$ & $\begin{array}{l}99^{*} \\
\pm 10\end{array}$ & $\begin{array}{l}100^{*} \\
\pm 10\end{array}$ & $\begin{array}{l}72+ \\
\pm 14\end{array}$ & $\begin{array}{l}78+ \\
\pm 15\end{array}$ \\
\hline $\begin{array}{l}\text { Peripheral vascular } \\
\text { resistance (PRU) }\end{array}$ & $\begin{array}{l}25.2 \\
\pm 2.3\end{array}$ & $\begin{array}{l}24.0 \\
\pm 1.7\end{array}$ & $\begin{array}{l}23.9 \\
\pm 1.9\end{array}$ & $\begin{array}{l}23.9 \\
\pm 1.8\end{array}$ & $\begin{array}{l}24.1 \\
\pm 1.9\end{array}$ & $\begin{array}{l}24.3 \\
\pm 1.8\end{array}$ & $\begin{array}{l}24.6 \\
\pm 1.7\end{array}$ & - & - \\
\hline $\begin{array}{l}\text { Antidiuretic hormone } \\
\text { (pg/ml) }\end{array}$ & $\begin{array}{l}5 \\
\pm 2\end{array}$ & $\begin{array}{l}4 \\
\pm 2\end{array}$ & $\begin{array}{l}4 \\
\pm 2\end{array}$ & $\begin{array}{l}5 \\
\pm 2\end{array}$ & $\begin{array}{l}5 \\
\pm 2\end{array}$ & $\begin{array}{l}6 \\
\pm 3\end{array}$ & $\begin{array}{l}4 \\
\pm 2\end{array}$ & $\begin{array}{l}35+ \\
\pm 6\end{array}$ & $\begin{array}{l}47+ \\
\pm 8\end{array}$ \\
\hline
\end{tabular}

$* P<0.05$

$+P<0.01$, Student's paired t-test when compared to control values.

Plasma ADH was assayed by the radioimmunoassay technique of Philbin and coworkers. ${ }^{3}$ During operation increments of pancuronium 1 to $3 \mathrm{mg}$ were given intravenously as necessary. Additional fentanyl was administered at a rate of $300 \mu \mathrm{g} / \mathrm{min}$ whenever $\overline{\mathrm{BP}}, \mathrm{HR}$ or $\mathrm{Q} T$ increased 15 per cent or more above preanaesthetic (control) values.

Postoperatively patients had their respiration controlled until consciousness returned. Two hours after return of consciousness they were placed on a $T$-piece apparatus with 40 per cent inspired oxygen and allowed to breathe spontaneously. When patients could sustain $\mathrm{Pa}_{\mathrm{CO}}$ of less than $5.32 \mathrm{kPa}$ ( 40 torr) and a $\mathrm{Pa}_{\mathrm{O}_{2}}$ of more than $13.3 \mathrm{kPa}$ (100 torr) for one hour, had a respiratory rate above 12 and could generate a negative inspiratory pressure of $2.66 \mathrm{kPa}$ ( 20 torr) or greater, they were extubated.

Data were analyzed for statistical significance using Student's paired t-test for comparison to control (pre-fentanly) values.

\section{RESULTS}

Unresponsiveness was produced by an average of $1659 \mu \mathrm{g}\left(25 \mu \mathrm{g} \cdot \mathrm{kg}^{-1}\right)$ of fentanyl. Patients received an average of $4640 \mu \mathrm{g}\left(71 \mu \mathrm{g} \cdot \mathrm{kg}^{-1}\right)$ of fentanyl for the entire operation. Fentanyl $\left(20 \mu \mathrm{g} \cdot \mathrm{kg}^{-1}\right)$ produced a small but significant reduction of $H R$ and $\overline{B P}$ but did not significantly change SV, Qr, or PVR (Table I). Additional fentanyl did not further alter $\mathrm{HR}$ or $\overline{\mathrm{BP}}$ nor change any other variable measured.

Neither intubation nor surgical stimulation significantly altered any cardiovascular variable measured. Cardiopulmonary bypass was associated with a lower $\overline{\mathbf{B P}}$ but no change in $\bar{Q} T$ when compared to pre-anaesthetic control values.

Plasma ADH was not significantly changed from pre-anaesthetic values by any dose of fentanyl, tracheal intubation or surgical stimulation (Table I). Both 15 and 60 minutes of cardiopulmonary bypass produced significant increases in plasma ADH. No patient remembered any aspect of the operation nor experienced an increase of $\widehat{\mathrm{BP}}$ or HR greater than 20 per cent of control (pre-anaesthesia) values at any time during or immediately after operation. Successful tracheal extubation was accomplished in all patients an average of $5.1 \pm 1.8$ hours (range 3 to 9 hours) after operation without the need of narcotic antagonists.

\section{Discussion}

This study demonstrates that larges doses of fentanyl are capable of producing complete anaesthesia and minimal changes in cardiovascular dynamics in patients with coronary artery disease. It also indicates that high-dose fentanyl anaesthesia blocks the increases in plasma antidiuretic hormone, arterial blood pressure and heart rate which are so common with morphine 
and other anaesthetic techniques during tracheal intubation and surgical stimulation in patients with coronary artery disease. Our findings suggest that fentanyl-oxygen anaesthesia is an attractive technique in patients with coronary artery disease.

The metabolic response to trauma, shock, and surgical stress generally produces increases in circulating blood levels of glucocorticoids, aldosterone, adrenocorticotropic hormone (ACTH), antidiuretic hormone, human growth hormone, and catecholamines (epinephrine and norepinephrine), thyroid hormone, glucose, free fatty acids and lactate. ${ }^{4}$ Most general anaesthetic techniques, while frequently altering or modifying metabolic responses to surgical trauma, do not prevent these changes. Whether alteration or blockade of the stress response to surgery is advantageous or not is a debatable point. Certainly there are patients with markedly impaired preoperative myocardial dynamics who depend on elevated circulating levels of epinephrine and/or norepinephrine to maintain circulatory integrity, such as patients with severe mitral stenosis and markedly reduced cardiac output. ${ }^{5.6}$ Increased plasma levels of the catecholamines and perhaps other compounds, secondary to operative stress, may be of benefit to these patients. On the other hand, increased plasma concentrations of the catecholamines and the other stress responding endocrines and compounds and the secondary haemodynamic and metabolic changes they produce can be detrimental to patients with other pathological processes, such as ischaemic heart disease.

Patients with coronary artery disease suffer from an unbalancing of the myocardial blood flow (oxygen) requirement to supply ratio. ${ }^{7}$ Increases of heart rate, arterial blood pressure, myocardial contractility, ventricular filling pressures and pulmonary and systematic vascular resistances further unbalance the ratio and can not only lead to more marked ischaemia and angina, but to myocardial infarction as well. ${ }^{7.8}$ It is therefore important to avoid anaesthetic techniques which produce cardiovascular stimulation in patients with coronary artery disease. Indeed, there is evidence that mild decreases in arterial blood pressure and heart rate may be beneficial to these patients. ${ }^{9.10}$

This study demonstrates that large doses of fentanyl produce mild decreases of heart rate and arterial blood pressure but do not significantly alter cardiac output. Plasma ADH, the stress responding hormone we were able to measure in this study, was not changed by fentanyl. Furthermore, tracheal intubation and surgical stimulation, stressful actions which frequently provoke significant increases in heart rate and arterial blood pressure " as well as $A \mathrm{DH}^{12}$ and other stress responding hormones, did not significantly alter either the cardiovascular variables measured or plasma ADH. This suggests that the patients were deeply anaesthetized. When questioned postoperatively, no patient experienced pain during operation or remembered any aspect of tracheal intubation or operation, confirming the adequacy of the anaesthesia produced by fentanyl.

Investigations in this laboratory ${ }^{13}$ and others ${ }^{14}$ have demonstrated that large doses of morphine ( 0.5 to $3 \mathrm{mg} \cdot \mathrm{kg}^{-1}$ ) as the sole anaesthetic plus oxygen also produce minimal reductions in heart rate and arterial blood pressure and do not alter cardiac output in patients with coronary artery disease. Unfortunately, these doses of morphine frequently produce incomplete anaesthesia.s and, even more troublesome, do not always block surgically induced increases in arterial blood pressure, heart rate and plasma $\mathrm{ADH}$ in patients with coronary artery disease. ${ }^{11.16}$ Larger doses of morphine $\left(8-11 \mathrm{mg} \cdot \mathrm{kg}^{-1}\right)$ will prevent surgical stimulation of the cardiovascular system but will necessitate the administration of significantly greater amounts of blood or other colloids and may produce prolonged respiratory depression. ${ }^{17.6}$ Indeed, respiratory depression preventing tracheal extubation has been observed to last as long as $\mathbf{3 2}$ hours after operation following morphine anaesthesia and averages two to three hours longer in patients with coronary artery disease receiving morphine $\left(8-11 \mathrm{mg} \cdot \mathrm{kg}^{-1}\right)$ than comparable amounts of fentanyl as in this study. Use of the potent inhalation agent enflurane can prevent stimulation of the cardiovascular system and increases of ADH during operation but is associated with significant decreases in arterial blood pressure and cardiac output. ${ }^{19}$

Plasma ADH was significantly increased during cardiopulmonary bypass in this study. Similar increases have been reported during bypass by Philbin and Coggins ${ }^{12}$ and by $\mathrm{Wu}$ and Zbuzkova* using a different technique. However, in both those studies plasma ADH increased initially with surgical stress before bypass. While the exact mechanism producing increase of plasma ADH during bypass is unknown, it has been

*Wu, W., and ZbuzKova, V. Vasopressin levels during cardiac surgery. A.S.A. Abstracts of Scientific Papers, p. 585 (1977) 
shown that addition of blood to the normal crystalloid (lactated Ringer's) priming volume of the extracorporeal circuit and rewarming during extracorporeal circulation does not prevent these changes. ${ }^{12}$ It has been suggested that introduction of the unphysiological state of cardiopulmonary bypass produces a marked stress response which results in an outpouring of $A D H .{ }^{12}$ Our data are consistent with this suggestion. Furthermore, our findings indicate that the stress response to cardiopulmonary bypass is significantly greater than that of operation before bypass, as the latter can be blocked with high doses of fentanyl while the former cannot.

\section{SUMMARY}

This study demonstrates that larges doses of fentanyl, as the sole anaesthetic with ventilation with oxygen, produces complete anaesthesia and minimal changes in cardiovascular dynamics in patients with coronary artery disease. It also indicates that high dose fentanyl anaesthesia blocks the increases in plasma anti-diuretic hormone and cardiovascular dynamics which are so common with morphine and other anaesthetic techniques during tracheal intubation and surgical stimulation in patients with coronary artery disease. Our findings suggest that fentanyl-oxygen anaesthesia is an attractive technique in patients with coronary artery disease.

\section{RÉSUMÉ}

Dans cette étude portant sur 14 malades opérés pour pontage aortocoronarien, les auteurs ont mesuré la réponse du système cardiovasculaire et de l'hormone antidiurétique à des doses anesthésiques de fentanyl (20-80 $\left.\mu \mathrm{g} \cdot \mathrm{kg}^{-1}\right)$; les observations ont été faites avant et pendant la stimulation chirurgicale et en cours de circulation extracorporelle.

$A$ ces doses de fentanyl, on observe une lëgère augmentation de la fréquence cardiaque et de la pression artérielle moyenne, mais sans modification du volume systolique, du débit cardiaque et de la résistance vasculaire périphérique. Le taux plasmatique de l'hormone antidiurétique n'est pas modifié de façon significative par le fentanyl, quels qu'en soient la dose, l'incubation, ou le stimulus chirurgical, quelle qu'en soit l'intensité; par contre, on note une augmentation significative de l'ADH plasmatique au cours de la circulation extracorporelle.
Cess données montrent que chez le porteur de maladie coronarienne, de fortes doses de fentanyl associées à de l'oxygène pur, produisent une anesthésie complète; on ne note que des effets mineurs sur la dynamique cardiovasculaire et la production d'hormone antidiurétique avant toute stimulation chirurgicale ou pendant celle-ci. Ces données inclinent à penser que la combinaison fentanyl-oxygène apparaît recommandable pour lanesthésie du malade coronarien.

\section{ReFERENCES}

1. Stanley, T.H. \& Webster, L.R. Anesthetic requirements and cardiovascular effects of fentanyl-oxygen and fentanyl-diazepam-oxygen anesthesia in man. Anesth. Analg. 57: 411 (1978).

2. Warner, H.R., Gardner, F.M., \& Toronto, A.R. Computer-based monitoring of cardiovascular functions in postoperative patients. Circulation 38 (supple II): 68 (1968).

3. Philain, D.M., Wilson, N.E., Sokoloskı, J. \& Coccins, $C$. Radioimmunoassay of antidiuretic hormone during morphine anaesthesia. Canad. Anaesth. Soc. J. 23: 290(1976).

4. Oyama, T. Anesthetic management of endocrine disease, R. Frey, F. Kern, O. Mayrhofer, Editors, New York, Springer-Verlag, Chap. 4.

5. YOSHIDA, Y. Studies on the pathologic physiology of pulmonary hypertension in mitral valve disease: I. The role of the sympathetic nervous system on the increment of pulmonary vascular resistance. Jap. Arc. J. 33: 359 (1969).

6. STANLEy, T.H. ISERN-AMaral, J., LATHROP, G.D. Urine norepinephrine excretion in patients undergoing mitral or aortic valve replacement with morphine anesthesia. Anesth. Analg. 54: 509 (1975).

7. Braunwald, E. Control of myocardial oxygen consumption: physiologic and clinical considerations. Am. J. Cardio. 27: 416(1971).

8. Kaplan, J.A., Dunbar, R.W., \& Jones, E.L. Nitroglycerin infusion during coronary-artery surgery. Anesthesiology 45: $14(1976)$

9. Bland, J.H.L. \& LoweNSTEIN, E. Halothaneinduced decreases in experimental myocardial ischemia in the non-failing canine heart. Anesthesiology 45: 287 (1976).

10. HamiLton, W.K. Do let the blood pressure drop and do use myocardial depressants. Anesthesiology 45: 273 (1971).

11. ARENS, J.F., BENBow, B.P., \& OChSNER, J.L. Morphine anesthesia for aortocoronary artery bypass procedures. Anesth. Analg. S1: 901 (1972).

12. Philbin, D.M. \& Cocgins, C.H. Plasma vasopressin levels during cardiopulmonary bypass with and without profound haemodilution. Canad. Anaesth. Soc. J. 25: 282 (1978).

13. Stanley, T.H., Gray, N.N., \& Bidwal, A.V. The effects of high dose morphine and morphine plus nitrous oxide on urinary output in man. Canad. Anaesth. Soc. J. 21: 379 (1974).

14. Lowenstein, E., Hallowell, P., \& Levine, F.J. Cardiovascular response to large doses of in- 
travenous morphine in man. N. Engl. J. Med. 281: 1389 (1969).

15. Lowenstein, E. Morphine "Anesthesia" - A Perspective. Anesthesiology 25: 563 (1971).

16. Philbin, D.M. \& Coggins, C.H. Plasma antidiuretic hormone levels in cardiac surgical pa. tients during morphine and halothane anesthesia. Anesthesiology 49:95 (1978).

17. Stanley, T.H. \& Gray, N.H. The effects of high dose morphine on blood and fluid requirements of open-heart operations. Anesthesiology 38: 536 (1973).
18. Stanley, T.H. \& Lathrop, G.D. Urinary excretion of morphine during and after valvular and coronary-artery surgery. Anesthesiology 46: 166 (1977).

19. Hill., E.G., Stanley, T.H., Hodges, M.R., SEnTKer, C.R., \& PhILBIN, D. Failure of enflurane in altering renal responses to acute intracranial pressure increases. Anesth. Analg. 57: 200 (1978). 